\title{
Large Mass, Entry, Descent and Landing Sensitivity Results for Environmental, Performance, and Design Parameters
}

\author{
Jeremy D. Shidner ${ }^{1}$ \\ Binera Inc., Hampton, VA, 23681 \\ Jody L. Davis ${ }^{2}$, Alicia D. Cianciolo ${ }^{3}$, and Jamshid A. Samareh ${ }^{4}$ \\ NASA Langley Research Center, Hampton, VA, 23681 \\ and \\ Richard W. Powell ${ }^{5}$ \\ Analytical Mechanics and Associates Inc., Hampton, VA, 23681
}

\begin{abstract}
Landing on Mars has been a challenging task. Past NASA missions have shown resilience to increases in spacecraft mass by scaling back requirements such as landing site altitude, landing site location and arrival time. Knowledge of the partials relating requirements to mass is critical for mission designers to understand so that the project can retain margin throughout the process. Looking forward to new missions that will land 1.5 metric tons or greater, the current level of technology is insufficient, and new technologies will need to be developed. Understanding the sensitivity of these new technologies to requirements is the purpose of this paper.
\end{abstract}

\section{Nomenclature}

$\begin{array}{ll}\text { AS } & =\text { Aeroshell } \\ E D L & =\text { Entry, Descent and Landing } \\ E D L-S A & =\text { Entry, Descent and Landing Systems Analysis } \\ g & =\text { Standard Earth Gravity Acceleration } \\ H I A D & =\text { Hypersonic Inflatable Aerodynamic Decelerator } \\ I A D & =\text { Inflatable Aerodynamic Decelerator } \\ l b f & =\text { Pounds Force } \\ l b m & =\text { Pounds Mass } \\ L / D & =\text { Lift-to-Drag ratio } \\ L S A I D & =\text { Lifting Supersonic Inflatable Aerodynamic Decelerator } \\ L H I A D & =\text { Lifting Hypersonic Inflatable Aerodynamic Decelerator } \\ M T & =\text { Metric Ton } \\ S A I D & =\text { Supersonic Inflatable Aerodynamic Decelerator } \\ \text { TPS } & =\text { Thermal Protection System }\end{array}$

\section{Introduction}

THE Mars Entry, Descent, and Landing Systems Analysis (EDL-SA) task was initiated in 2008 to identify new candidate technologies to be used to deliver large payloads to the surface. Year 1 of the EDL-SA study, as a follow

\footnotetext{
${ }^{1}$ Aerospace Engineer, Atmospheric Flight \& Entry Systems Branch/D205, MS 489, AIAA Member.

${ }^{2}$ Aerospace Engineer, Atmospheric Flight \& Entry Systems Branch/D205, MS 489, AIAA Member.

${ }^{3}$ Aerospace Engineer, Atmospheric Flight \& Entry Systems Branch/D205, MS 489, AIAA Member.

${ }^{4}$ Research Mathematician, Systems Analysis \& Concepts Directorate/D205, MS 451, AIAA Member.

${ }^{5}$ Senior Aerospace Engineer, Atmospheric Flight \& Entry Systems Branch/D205, MS 489, AIAA Member.
} 
on to the EDL portion of the Mars Design Reference Architecture 5.0 ${ }^{1}$, focused on expanding the trade space of EDL technologies to determine which should be recommended for further study. The technologies considered include inflatable aerodynamic decelerators (IAD), rigid mid range lift-to-drag (L/D) aeroshells, and supersonic retro-propulsion. The technologies were arranged to form eight unique exploration class mission architectures that are listed in Table 1 and conceptually illustrated in Figure 1. Of these eight architectures, sensitivity analyses were performed to identify the potential mass savings of the proposed combination of technologies given changes in environment, performance and design. The sensitivities for Architecture 3, 4, and 5 are not presented because of the all-propulsive design of Architecture 3 and the duplication of EDL design for Architectures 4 and 5.

The sensitivities are evaluated in this paper by examining their effect on mass, safety, and reliability. For example, the sensitivity of IAD diameter to landed payload mass for vehicles with the same ballistic coefficient is explored. The results illustrate the advantage of IAD's for larger masses assuming the larger reference drag area can be accommodated with minimal impact on mass. Such sensitivities will be important to technology development programs as they decide what investments to make.

Table 1: Architecture Descriptions

\begin{tabular}{|l|l|l|l|l|}
\hline & Aerocapture & Hypersonic & Supersonic & Subsonic \\
\hline Architecture 1 & Rigid Mid-L/D AS & Rigid Mid-L/D AS & Propulsion & Propulsion \\
\hline Architecture 2 & Lifting HIAD & Lifting HIAD & Propulsion & Propulsion \\
\hline Architecture 3 & N/A & Propulsion & Propulsion & Propulsion \\
\hline Architecture 4 & Rigid Mid-L/D AS & Lifting HIAD & Propulsion & Propulsion \\
\hline Architecture 5 & Rigid Mid-L/D AS & Lifting HIAD & Same LHIAD & Propulsion \\
\hline Architecture 6 & Lifting HIAD & Lifting HIAD & Same LHIAD & Propulsion \\
\hline Architecture 7 & Rigid Mid-L/D AS & Rigid Mid-L/D AS & Drag SIAD & Propulsion \\
\hline Architecture 8 & Lifting HIAD & Lifting HIAD & LSAID-Skirt & Propulsion \\
\hline
\end{tabular}

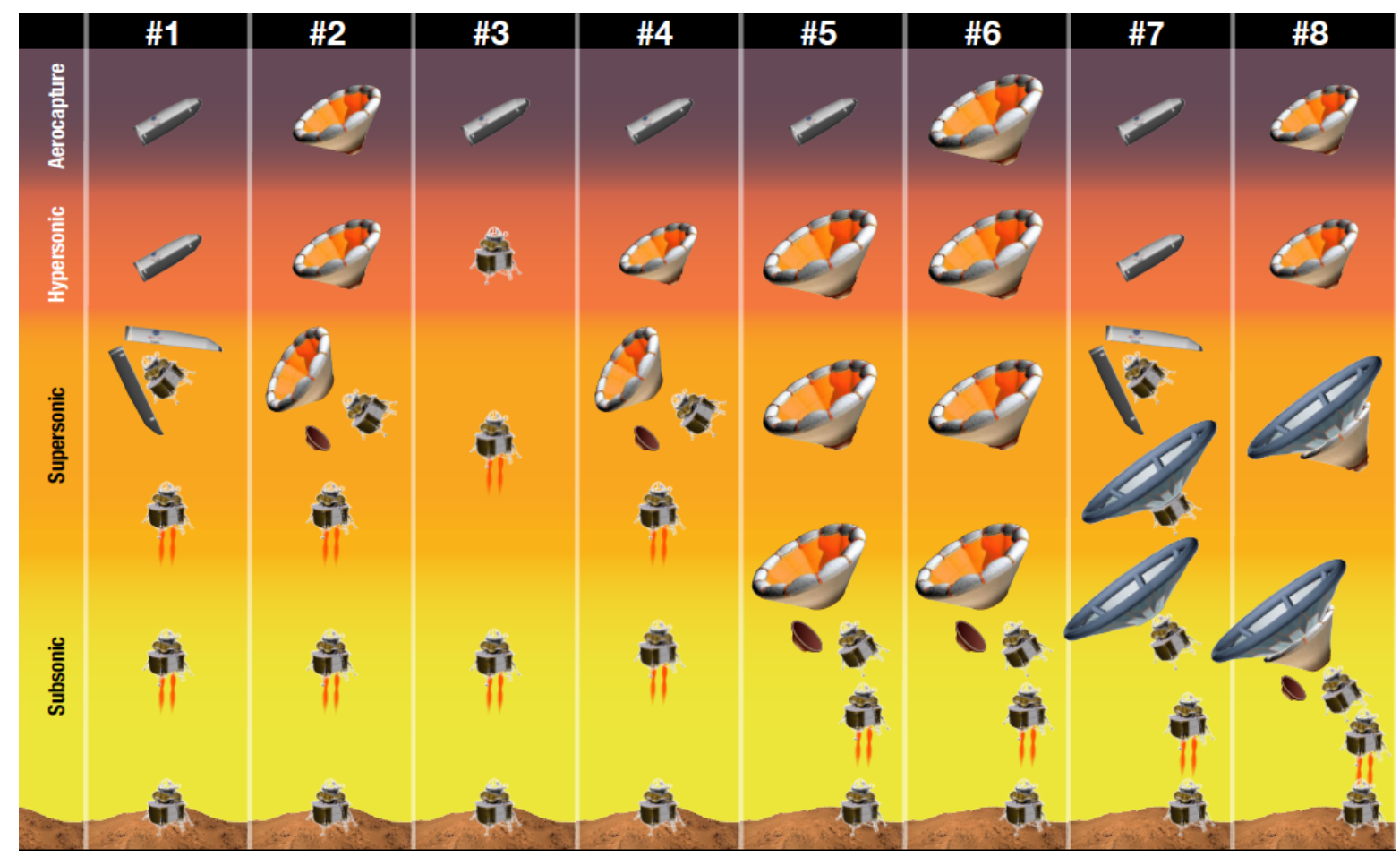

Figure 1: Exploration Class Architectures

All of the sensitivities were performed using the EDL-SA simulation, Program to Optimize Simulated Trajectories II (POST2) ${ }^{2}$. The set of constraints was identical for all architectures: (1) do not exceed a peak earth gload of 4 g's so as not to exceed Human Systems Integration Requirements, (2) do not exceed an engine throttle of 
$80 \%$ such that margin is retained, and (3) utilize the same guidance strategy ${ }^{3}$ of a two phase, bank angle controlled, lifting vehicle in all cases. The first guidance phase, called range-control, converges the range-to-target, terminating at a fixed velocity condition. The second phase, called heading alignment, converges heading alignment error to the target, terminating at the $80 \%$ throttle engine ignition conditions. The sensitivity study utilized a mass model ${ }^{4}$ such that the sensitivity parameters produced an individually optimized concept for each value. The mass model ensures that the amount of fuel, structure, Thermal Protection System (TPS), and system components are adequate to meet the sensitivity parameters. All of the sensitivities were performed on entries from a 1-sol and 500 kilometer orbit, adjusting each initial orbit's argument of periapse and longitude of the ascending node such that the final trajectory ended at the designated target.

\section{Environmental Sensitivities}

The environmental sensitivity study separately varied season $\left(\mathrm{L}_{\mathrm{s}}\right)$, dust opacity, landing altitude above MOLA, latitude and time of day at Mars in the nominal trajectory of each architecture. Other environmental sensitivities such as winds and non steady-state density perturbations were varied in Monte Carlo analysis not shown here. The metric used to judge the environmental sensitivity was variation in entry mass, due to the extra fuel, TPS material, and system components that were deemed necessary by the mass model for the architecture to converge for the given environmental dispersions.

The environmental sensitivity that had the largest effect on deorbit mass was landing site altitude. The greatest sensitivity is seen in architectures 1 and 2, having 3.5\% variation in entry mass across the landing altitudes of -4 to 2.5 kilometers. The entry mass variation is amplified when considering entry for the 500 kilometer circular orbit, as shown in Figure 2. For the architectures where supersonic retropropulsion is not needed, the variation in entry mass was greatly alleviated with Architecture 8 performing the best with $0.6 \%$ variation in entry mass.

The sensitivity to atmospheric variability was split into two sets of parameters, season or solar longitude and dust opacity. Past observations of Mars have shown dust opacity exceeding values of 3.0, however for a mission entering from orbit, it was assumed that a dust storm could be avoided by waiting to deorbit at an optimal time. Therefore, the dust opacity was only varied from 0.1 to

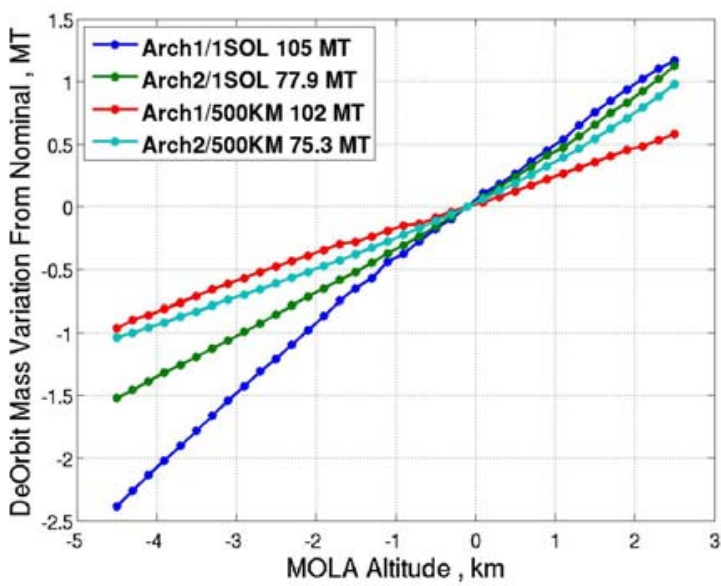

Figure 2: Effect of Landing Site Altitude on Entry Mass 0.9. The sensitivity to solar longitude is a measure of the seasonal pressure cycle on Mars, thus varying the mean density across the expected range on Mars. Sensitivity to season and dust opacity was minimal, with architecture 2 having the greatest sensitivity of $1.1 \%$ variation in entry mass at the extreme of the season/dust opacity values. Architectures 7 and 8 have the least sensitivity with approximately $0.5 \%$ variation in entry mass. The primary driver in the variation in entry mass was due to the fuel use on powered descent, stemming from the variation in velocity at engine ignition.

The sensitivity to latitude varied inconsistently across the architectures. The variations in entry mass were found to come from the enforcement of the guidance strategy and the fixed heading alignment velocity. As heading alignment velocity varied for different target latitudes, so would the fuel use during powered descent. This implied that even though entry mass variation was noticeable for latitude sensitivity, the variation could be mitigated by adjusting the guidance heading alignment trigger.

The sensitivity to time of day was insignificant across the range of architectures studied. Entry mass varied cyclically as would be expected for the shifts in atmosphere throughout one Martian day. Peak variation in entry mass was seen in Architecture 2 as $0.8 \%$ while Architecture 8 had the least variation of $0.3 \%$.

Table 2 summarizes the results of the environmental sensitivities, quantified by total mass variation per architecture. This analysis shows that the exploration class vehicle performance, in terms of mass, is insensitive to environmental effects. The best performing architectures were those with multiple transitions, Architectures 7 and 8 , while Architectures 1 and 2 were more susceptible to the environmental variability. 
Table 2: Environmental Sensitivity

\begin{tabular}{|c|c|c|c|c|c|c|c|}
\hline \multirow{2}{*}{$\begin{array}{r}\text { Sensitivity } \\
\text { Architecture }\end{array}$} & \multirow[t]{2}{*}{$\begin{array}{l}\text { Nominal } \\
\text { Value }\end{array}$} & \multirow[t]{2}{*}{$\begin{array}{l}\text { Sensitivity } \\
\text { Range }\end{array}$} & \multicolumn{5}{|c|}{$\begin{array}{l}\text { Total Mass Variation }(\mathrm{kg}) \\
\text { ( \%) of total entry mass }\end{array}$} \\
\hline & & & 1 & 2 & 6 & 7 & 8 \\
\hline Season (Ls) & $\sim 174.5$ & 0:30:360 deg & 688 & 863 & 660 & 334 & 367 \\
\hline $\begin{array}{c}\text { Dust opacity } \\
\text { MarsGRAM dusttau }\end{array}$ & 0.7 & 0.1:0.2:0.9 & $(0.7 \%)$ & $(1.1 \%)$ & $(0.7 \%)$ & $(0.4 \%)$ & $(0.5 \%)$ \\
\hline $\begin{array}{l}\text { Landing Altitude } \\
\text { Above MOLA }\end{array}$ & $0 \mathrm{~km}$ & $-4: 0.2: 2.5 \mathrm{~km}$ & $\begin{array}{c}3724 \\
(3.6 \%)\end{array}$ & $\begin{array}{c}2582 \\
(3.4 \%)\end{array}$ & $\begin{array}{l}1860 \\
(2 \%)\end{array}$ & $\begin{array}{l}1075 \\
(1.1 \%)\end{array}$ & $\begin{array}{c}464 \\
(0.6 \%)\end{array}$ \\
\hline Latitude & -1.177 & $-75: 15: 75$ deg & $\begin{array}{c}1555 \\
(1.5 \%)\end{array}$ & $\begin{array}{c}2053 \\
(2.7 \%)\end{array}$ & $\begin{array}{c}2146 \\
(2.3 \%)\end{array}$ & $\begin{array}{c}941 \\
(1 \%)\end{array}$ & $\begin{array}{c}890 \\
(1.2 \%)\end{array}$ \\
\hline Time of Day & $5: 30 \mathrm{am}$ & 0:1.5:24 hours & $\begin{array}{c}591 \\
(0.6 \%)\end{array}$ & $\begin{array}{c}574 \\
(0.8 \%)\end{array}$ & $\begin{array}{c}494 \\
(0.5 \%)\end{array}$ & $\begin{array}{c}430 \\
(0.4 \%)\end{array}$ & $\begin{array}{c}226 \\
(0.3 \%)\end{array}$ \\
\hline
\end{tabular}

\section{Performance Sensitivities}

The performance sensitivity study varied engine thrust-to-weight, specific impulse and retro-propulsion aerodynamics of each architecture's nominal trajectory. The goal of the performance sensitivities is to show the benefit of trades that can be made with engine design and placement. Engine placement is motivated from historical investigations to supersonic retro-propulsion that indicates drag performance can be augmented. The engine design used in the mass model is LOX/CH4 that is sized for various levels of thrust-to-weight. By changing the engine and vehicle thrust-to-weight, the powered descent sensitivity could be analyzed.

The performance sensitivities focus primarily on the powered descent portion of the simulation, which utilizes a simple gravity turn and linear altitude verses velocity profile to fly by throttling the engines. This type of powered descent approach causes the majority of the thrust to be used in the beginning while keeping more benign thrust levels at the end of the powered descent profile such that hazards can be avoided near touchdown. Once the vehicle slows to a velocity of 2.5 meters per second, a 10 second constant velocity phase is modeled before touchdown.

The sensitivity of entry mass to engine and vehicle thrustto-weight is minimal for small improvements in engine thrustto-weight performance. Figure 3 shows the variation in entry mass and variation in altitude at engine ignition for various thrust-to-weights in Architecture 2. The results indicate an optimum vehicle thrust-to-weight around 2.5 g's and engine thrust-to-weight around $80 \mathrm{lbf} / \mathrm{lbm}$. However, entry mass is not the only metric to consider for thrust-to-weight, as engine thrust is important for safely landing the payload under dispersed conditions. For greater vehicle thrust-to-weight, a lower altitude can be tolerated before having to ignite the engines, however this compresses the timeline for powered descent. Depending on the powered descent strategy, decreased timeline can be harmful if the vehicle does not have the sensor performance to accurately navigate to the ground in that time. However, with longer times spent in powered

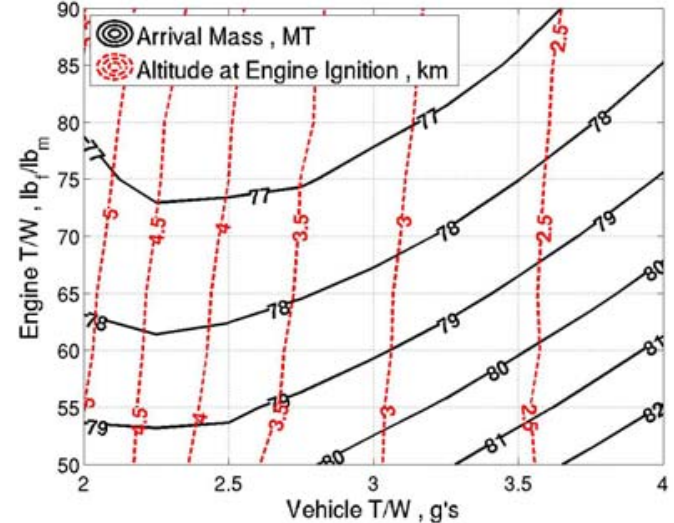

Figure 3: Sensitivity to Thrust to Weight for Architecture 2 descent, dispersions can stretch that timeline, further amplifying gravity losses during powered descent, increasing fuel use. By choosing an appropriate vehicle thrust-to-weight, a balance can be achieved between risk and fuel use.

The sensitivity of entry mass to specific impulse is minimal due to the short amount of time spent in powered descent. The stressing case for powered descent is Architecture 1, spending 73 seconds on the engines due to the 
high velocity at engine ignition. This stress case only achieves a $0.6 \%$ improvement in entry mass for a 10 second improvement in specific impulse.

The sensitivity of entry mass to supersonic retropropulsion drag augmentation is minimal, due to the small benefit aerodynamic drag provides during powered descent. Calculating the velocity losses during powered descent shows that the aerodynamic drag accounts for $2.5 \%$ of the delta-v removed from the system during powered descent. This small delta-v only contributes about $0.1-0.2 \%$ variation in entry mass for a $10 \%$ increase axial drag coefficient.

Table 3 summarizes the Performance Sensitivity results for Architectures 1, 2 and 6 through 8 . The thrust-toweight sensitivity showed that, while it is important for powered descent performance, it is insensitive to arrival mass. Specific impulse variation for each of the architectures also showed insensitivity in that the low time-onengines result in a minimal effect of specific impulse on arrival mass. For supersonic retropropulsion drag augmentation, drag only accounts for $2.5 \%$ of powered descent $\Delta \mathrm{V}$, making the supersonic retro-propulsion aerodynamic augmentation insensitive and providing minimal benefit to arrival mass among all architectures.

Table 3: Performance Sensitivity

\begin{tabular}{|c|c|c|c|c|c|c|c|}
\hline \multirow{2}{*}{$\begin{array}{c}\text { Sensitivity } \\
\text { Architecture }\end{array}$} & \multirow{2}{*}{$\begin{array}{l}\text { Nominal } \\
\text { Value }\end{array}$} & \multirow{2}{*}{$\begin{array}{c}\text { Sensitivity } \\
\text { Range }\end{array}$} & \multicolumn{5}{|c|}{ Arrival Mass Change } \\
\hline & & & 1 & 2 & 6 & 7 & 8 \\
\hline $\begin{array}{l}\text { Engine Thrust } \\
\text { to Weight }\end{array}$ & $80 \mathrm{lb}_{\mathrm{f}} / \mathrm{lb}_{\mathrm{m}}$ & $50: 5: 90$ & $\begin{array}{c}-1.1 \mathrm{MT} \\
(-1 \%) / \\
10\left(\mathrm{lb}_{\mathrm{f}} / \mathrm{lb}_{\mathrm{m}}\right)\end{array}$ & $\begin{array}{c}-1 \mathrm{MT} \\
(-1.4 \%) / \\
10\left(\mathrm{lb}_{\mathrm{f}} / \mathrm{lb}_{\mathrm{m}}\right)\end{array}$ & $\begin{array}{c}-1.3 \mathrm{MT} \\
(-1.4 \%) / \\
10\left(\mathrm{lb}_{\mathrm{f}} / \mathrm{lb}_{\mathrm{m}}\right)\end{array}$ & $\begin{array}{c}-0.9 \mathrm{MT} \\
(-0.9 \%) / \\
10\left(\mathrm{lb}_{\mathrm{f}} / \mathrm{lb}_{\mathrm{m}}\right)\end{array}$ & $\begin{array}{c}-0.91 \mathrm{MT} \\
(-1.2 \%) / \\
10\left(\mathrm{lb}_{\mathrm{f}} / \mathrm{lb}_{\mathrm{m}}\right)\end{array}$ \\
\hline $\begin{array}{l}\text { Vehicle } \\
\text { Thrust to } \\
\text { Weight }\end{array}$ & $\begin{array}{l}3 \text { Earth } \\
\text { g's }\end{array}$ & $2: 0.25: 4$ & $\begin{array}{c}0.73 \mathrm{MT} \\
(0.7 \%) / g\end{array}$ & $\begin{array}{c}0.86 \mathrm{MT} \\
(1.1 \%) / g\end{array}$ & $\begin{array}{l}-0.91 \mathrm{MT} \\
(-1.0 \%) / g\end{array}$ & $\begin{array}{l}0.63 \mathrm{MT} \\
(0.7 \%) / g\end{array}$ & $\begin{array}{l}1.1 \mathrm{MT} \\
(1.5 \%) / \mathrm{g}\end{array}$ \\
\hline $\begin{array}{l}\text { Specific } \\
\text { Impulse }\end{array}$ & 369 sec & $355: 2.5: 375$ & $\begin{array}{c}-0.61 \mathrm{MT} \\
(-0.6 \%) / \\
10 \mathrm{sec}\end{array}$ & $\begin{array}{c}-0.43 \mathrm{MT} \\
(-0.6 \%) / \\
10 \mathrm{sec}\end{array}$ & $\begin{array}{c}-0.31 \mathrm{MT} \\
(-0.3 \%) / \\
10 \mathrm{sec}\end{array}$ & $\begin{array}{c}-0.24 \mathrm{MT} \\
(-0.2 \%) / \\
10 \mathrm{sec}\end{array}$ & $\begin{array}{c}-0.25 \mathrm{MT} \\
(-0.3 \%) / \\
10 \mathrm{sec}\end{array}$ \\
\hline $\begin{array}{c}\text { Supersonic } \\
\text { Aerodynamic } \\
\text { Augmentation }\end{array}$ & $\mathrm{Ca}=0$ & $\mathrm{Ca}=0: 2$ & $\begin{array}{c}-0.1 \mathrm{MT} \\
(-0.1 \%) / \\
10 \% \mathrm{Ca}\end{array}$ & $\begin{array}{l}-0.17 \mathrm{MT} \\
(-0.22 \%) \\
/ 10 \% \mathrm{Ca}\end{array}$ & $\mathrm{N} / \mathrm{A}$ & $\mathrm{N} / \mathrm{A}$ & $\mathrm{N} / \mathrm{A}$ \\
\hline
\end{tabular}

\section{Design Sensitivity}

The design sensitivity focused on the effect of varying the divert maneuver, extra propellant, payload and L/D. The goal of varying these parameters is to show the effect of mission design decisions that affect overall mission design of the architecture. The intent of these changes can often be related to reducing risk or cost of the mission. By knowing the gradient of these sensitivities to growth in entry mass, mission designers will be better suited to make design decisions.

The divert maneuver sensitivity is included to better understand the impact of utilizing a divert to avoid far-field recontact. Recontact analyses rely on, but are not limited to, the initial conditions at separation, ballistic coefficient mismatch and separation velocity between descent stage and aeroshell to assess the probability of recontact and to potentially determine the required size of divert. For this study a 2 kilometer divert maneuver was specified in the ground rules and assumptions as the necessary requirement to avoid recontact. This constant divert maneuver size will be shown to be inefficient as engine ignition velocity decreases, leading to the conclusion that a separate recontact analysis and divert requirement should be performed for lower engine ignition velocities. 
The divert maneuver is modeled by utilizing beta control to give the vehicle an angle of sideslip, thus incurring a side force from the body axis aligned thrust vector. The majority of the side slip is applied at the beginning of the powered descent trajectory to take advantage of the large amount of kinetic energy currently left in the system. The side slip is applied as a linear feedback function of heading alignment error to the target where the feedback is linearly decreased as velocity approaches zero.

The results of the divert maneuver sensitivity study are presented in Figure 4 as divert maneuver size on the $\mathrm{x}$-axis verses increased entry mass from a nominal no-divert trajectory along the y-axis. Sensitivity to entry mass is amplified for architectures 6 and 8 which have subsonic ignition velocities. Architecture 7 is listed but not shown due to the uncontrolled portion of the trajectory while on the supersonic inflatable aerodynamic decelerator making the heading error to large for the guidance to converge to the target. Architecture 1 performs the best, with only a 1.5 metric ton increase in arrival mass for a 2 kilometer divert.

The divert sensitivity results are primarily dependent on the need to include more fuel to handle varying powered descent profiles and dispersions. Figure 5 shows the growth in entry mass as a function of extra propellant remaining at touchdown for a no divert, powered descent profile. By comparing the arrival mass increase in Figure 4 to the corresponding increase in propellant in Figure 5, Architectures 6 and 8 are more inefficient for large diverts, requiring close to 2 metric tons more propellant to successfully divert only 0.5 to 1 kilometers. Architectures 1 and 2 are more fuel-efficient for large diverts, using less than 1 metric ton of extra propellant for 1 kilometer diverts.

The sensitivity to payload is included to understand the effect of increased payload mass on the total entry mass. Payload is modeled as landed usable mass on the Mars surface and does not include any of the EDL system mass. The obvious impact of extra payload mass is that the vehicle's ballistic coefficient is increased. With an increase in ballisitic

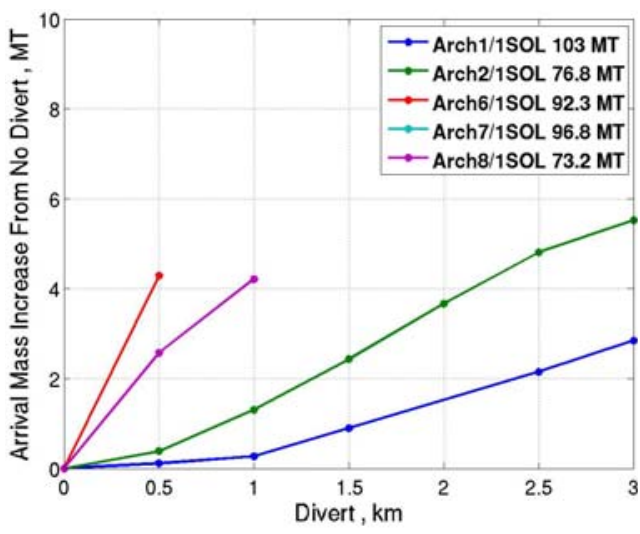

Figure 4: Divert Maneuver Sensitivity to Entry Mass

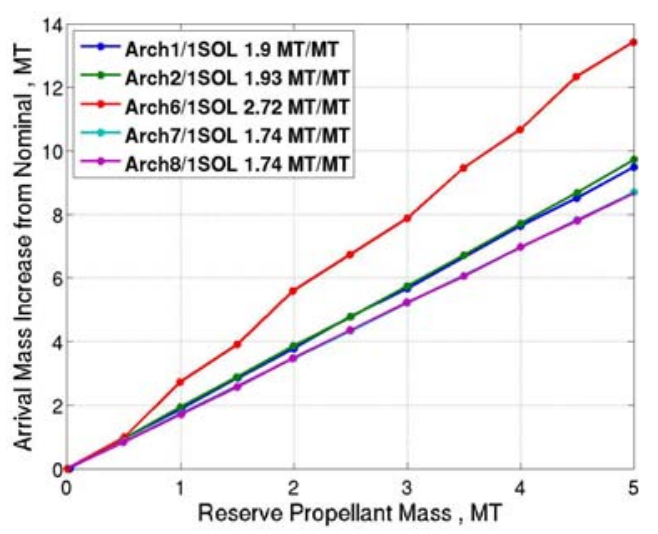

Figure 5: Entry Mass Growth as a Function of Remaining Propellant coefficient, often times other requirements like peak g load or heating during entry are affected. For Architectures 2, 6 , and 8 , the assumption is made that the inflatable diameter is easily changed, unlike the rigid aeroshell of Architectures 1 and 7. By changing the diameter, the ballistic coefficient can be tailored to accommodate the guidance and trajectory requirements for Architectures 2, 6, and 8 for varying payloads. Figure 6 shows the necessary inflatable diameters for Architectures 2, 6, 7, and 8, where Architectures 2 and 8 size the hypersonic inflatable to retain the same ballistic coefficient as the nominal 23 meter inflatable, while Architecture 6, 7 and 8 are sized to reach engine ignition conditions of Mach 0.8. Architecture 6 sizes the entry hypersonic inflatable to achieve the Mach 0.8 condition, while Architecture 7 sizes a supersonic inflatable deployed at Mach 4.5 and Architecture 8 sizes an extendable skirt deployed at Mach 3. The results of the payload sensitivity study showed linear trends in arrival mass verses payload mass with Architecture 6 being the most inefficient with 2.29 metric tons of entry mass growth for every metric ton of payload added, while Architecture 7 is the most efficient with 1.54 metric tons of entry mass growth for every metric ton of payload added.

Table 4 summarizes the results of the Design Sensitivities for each architecture. The L/D sensitivity looked at increasing L/D while maintaining the same vehicle ballistic number, which by increasing $\mathrm{L} / \mathrm{D}$ up to $10 \%$, has minimal sensitivity to arrival

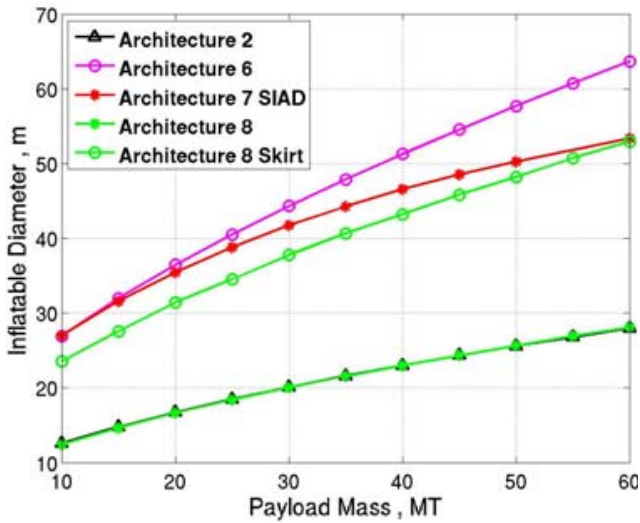

Figure 6: Inflatable Diameter for Various Payload Sizes 
mass. The divert maneuver is included to reduce the risk of aeroshell far-field recontact after separation and uses only beta control (modified gravity turn) to perform. For architectures with a low engine ignition velocity, the trajectory does not have the necessary energy to make large diverts. For large diverts, Architectures 6 and 8 are not optimal and provide the most sensitivity to arrival mass. Architectures 1 and 2 carry more energy at terminal descent ignition allowing for larger diverts, making them least sensitive with arrival mass. The payload sensitivity showed that mass growth is a linear relationship of arrival mass versus payload mass and showed similar linearity between each architecture.

Table 4: Design Sensitivity

\begin{tabular}{|c|c|c|c|c|c|c|c|}
\hline \multirow{2}{*}{$\begin{array}{l}\text { Sensitivity } \\
\text { Architecture }\end{array}$} & \multirow{2}{*}{$\begin{array}{l}\text { Nominal } \\
\text { Value }\end{array}$} & \multirow{2}{*}{$\begin{array}{l}\text { Sensitivity } \\
\text { Range }\end{array}$} & \multicolumn{5}{|c|}{ Arrival Mass Change } \\
\hline & & & 1 & 2 & 6 & 7 & 8 \\
\hline $\begin{array}{l}\text { Divert } \\
\text { Maneuver }\end{array}$ & $0 \mathrm{~km}$ & $0: 0.5: 3.0$ & $\begin{array}{c}-0.1 \mathrm{MT} \\
(-0.1 \%) / \\
0.5 \mathrm{~km}\end{array}$ & $\begin{array}{c}-0.3 \mathrm{MT} \\
(-0.4 \%) / \\
0.5 \mathrm{~km}\end{array}$ & $\begin{array}{c}-4.1 \mathrm{MT} \\
(-4.4 \%) / \\
0.5 \mathrm{~km}\end{array}$ & N/A & $\begin{array}{c}-2.5 \mathrm{MT} \\
(-3.4 \%) / \\
0.5 \mathrm{~km}\end{array}$ \\
\hline $\begin{array}{l}\text { Extra } \\
\text { Propellant }\end{array}$ & $0 \mathrm{MT}$ & $0: 0.5: 5.0$ & $\begin{array}{c}1.9 \mathrm{MT} \\
(1.84 \%) / \\
\text { MT Prop }\end{array}$ & $\begin{array}{l}1.93 \mathrm{MT} \\
(2.51 \%) / \\
\text { MT Prop }\end{array}$ & $\begin{array}{l}2.72 \mathrm{MT} \\
(2.95 \%) / \\
\text { MT Prop }\end{array}$ & $\begin{array}{l}1.74 \mathrm{MT} \\
(1.8 \%) / \\
\text { MT Prop }\end{array}$ & $\begin{array}{l}1.74 \mathrm{MT} \\
(2.4 \%) / \\
\text { MT Prop }\end{array}$ \\
\hline Payload & $40 \mathrm{MT}$ & $10: 5: 60$ & $\begin{array}{c}1.72 \mathrm{MT} \\
(1.67 \%) / \\
\text { MT } \\
\text { Payload }\end{array}$ & $\begin{array}{c}1.79 \mathrm{MT} \\
(2.33 \%) / \\
\text { MT } \\
\text { Payload }\end{array}$ & $\begin{array}{c}2.29 \mathrm{MT} \\
(2.48 \%) \\
\text { / MT } \\
\text { Payload }\end{array}$ & $\begin{array}{c}1.54 \mathrm{MT} \\
(1.59 \%) \\
\text { / MT } \\
\text { Payload }\end{array}$ & $\begin{array}{c}1.71 \mathrm{MT} \\
(2.34 \%) \\
\text { / MT } \\
\text { Payload }\end{array}$ \\
\hline $\mathrm{L} / \mathrm{D}$ & $\begin{array}{l}0.51 \text { Rigid } \\
0.33 \text { Inflat }\end{array}$ & $75 \%: 125 \%$ & $\begin{array}{c}-0.782 \mathrm{MT} \\
(-0.76 \%) / \\
10 \% \mathrm{Lift}\end{array}$ & $\begin{array}{c}-0.485 \mathrm{MT} \\
(-0.63 \%) / \\
10 \% \mathrm{Lift}\end{array}$ & N/A & N/A & N/A \\
\hline
\end{tabular}

\section{Conclusion}

In summary, the EDL-SA exploration class architectures have shown no apparent cliff in entry mass penalties for the sensitivity studies analyzed and presented above. Architecture 6 was the most sensitive to design sensitivities due to the requirement to carry the same inflatable from entry to subsonic conditions. The subsonic engine ignition architectures were more sensitive to divert maneuvers, however could be alleviated by either igniting at a higher altitude or re-evaluating the divert requirements. Architectures with supersonic retro propulsion were more sensitive to landing site altitude due to the variable velocity at engine ignition while the subsonic engine ignition architectures held a near constant engine ignition velocity. Overall, each architecture has unique merits and provides an interesting and feasible approach for mission designers to consider for Mars entry, descent and landing of exploration class missions.

\section{References}

${ }^{1}$ Drake, B. G., editor. "Human Exploration of Mars Design Reference Architecture 5.0.” s.l. : NASA-SP-2009566, July 2009.

${ }^{2}$ Powell, R. W., Striepe, S. A., Desai, P. N., Queen, E. M., Brauer, G.L., Cornick, D. E., Olson, D. W., Petersen, F. M., Stevenson, R., Engle, M. C., Marsh, S. M., and Gromko, A.M., "Program to Optimize Simulated Trajectories (POST2), Vol. II Utilization Manual.” Version 1.1.6G, Jan 2004.

${ }^{3}$ Davis, J. L., Cianciolo, A. D., Powell, R. W., Shidner, J. D., Garcia-Llama, E., "Guidance and Control Algorithms for the Mars Entry Descent and Landing Systems Analysis.” AIAA/AAS Astrodynamics Specialist Conference, Toronto, Canada, August 2010.

${ }^{4}$ Samareh, J. A. and Komar D. R., “ Parametric Mass Modeling for Mars Entry, Descent, and Landing System Analysis Study,” 49th AIAA Aerospace Sciences Meeting in Orlando, FL, January 4-7, 2011 